\title{
Peningkatan Kesehatan Masyarakat Melalui Sosialisasi Penggunaan TOGA (Tanaman Obat Keluarga) Di Desa Tembobor
}

\author{
Dyke Gita Wirasisya $^{1)}$, Yohanes Juliantoni ${ }^{1)}$, Baghdawansyah Alqadri ${ }^{2)}$ \\ ${ }^{1,2}$ Program Studi Farmasi, Fakultas Kedokteran, Universitas Mataram. \\ ${ }^{3}$ Program Studi Pendidikan PPKN, Fakultas Keguruan dan Ilmu Pendidikan, \\ Universitas Mataram. \\ 11dykegita_w@unram.ac.id, 2 YY.juliantoni@unram.ac.id ${ }^{3}$ bagdaalqadri@gmail.com
}

\begin{abstract}
This community service was carried out in Tembobor village, North Lombok. This activity aims to improve family health and to reduce conventional healthcare cost by utilizing the TOGA (medicinal plants) for treatment, besides this activity is also intend to increase the use of the home backyard to plant medicinal plants. This community service are carried out in 2 process, the first process is the selection of medicinal plants that easily found in the society for medical purposes, the second process is to build "taman TOGA" in resident home backyard as a pilot project. From this activities we hope to enlighten and improve society knowledge in tembobor village on how to use medicinal plants and its planting techniques.
\end{abstract}

Keyword : TOGA, heatlh, tembobor village

\section{Abstrak}

Kegiatan pengabdian ini dilaksanakan di Desa Tembobor, Kabupaten Lombok Utara. Kegiatan ini bertujuan untuk meningkatkan kesehatan keluarga dan menekan biaya pengobatan konvensional dengan cara memanfaatkan penggunaan TOGA untuk pengobatan, selain itu kegiatan ini juga dilakukan untuk meningkatkan pemanfaatan pekarangan untuk menanam TOGA. Kegiatan pengabdian dilakukan dalam 2 tahap, tahap pertama yaitu sosialisasi pemanfaatan TOGA pilihan yang mudah didapatkan di lingkungan desa dan tahap kedua adalah melakukan penanaman TOGA pada salah satu pekarangan rumah warga untuk dijadikan percontohan. Hasil nyata yang didapatkan dari program ini adalah masyarakat Desa Tembobor mengetahui cara pemanfaatan TOGA dan mulai untuk melakukan penanaman

Kata Kunci : TOGA, kesehatan, desa tembobor

\section{PENDAHULUAN}

Indonesia merupakan negara dengan biodiversitas yang tinggi sehingga kaya akan berbagai tanaman obat yang sangat potensial untuk dikembangkan namun belum dikelola dan dimanfaatkan secara optimal. Masyarakat lebih percaya untuk menggunakan obat konvensional dibandingkan tanaman obat. Penggunaaan tanaman obat dianggap kuno dan tidak banyak memberikan hasil. Baru beberapa tahun belakangan ini ada kecenderungan untuk kembali ke alam atau "back to nature" membuat masyarakat kembali kepada tanaman obat. Hal itu tidak terlepas dikarenakan beberapa kelemahan obat konvensional antara lain terdapat efek samping, resistensi obat yang tinggi, terakumulasi di tubuh dan harganya pun cenderung lebih mahal. Selain kecenderungan "back to nature", keadaan krisis ekonomi berkepanjangan yang melanda Indonesia membuat biaya kesehatan semakin mahal. Beberapa obat konvensional sudah menjadi barang mewah bagi sebagian besar masyarakat sehingga berbagai tanaman berkhasiat obat mulai di lirik kembali sebagai 
DOI: https://doi.org/10.21009/sarwahita.151.07

P-ISSN: 0216-7484

E-ISSN: 2597-8926

pengobatan alternatif (Peraturan Menteri

Kesehatan Republik Indonesia, 2008).

Terdapat 31 jenis tanaman yang dapat digunakan sebagai bahan baku industri obat tradisional (jamu), industri non jamu, bumbu maupun kebutuhan ekspor. Namun hanya sekitar 20-30\% dari tanaman obat tersebut yang sudah dibudidayakan. Sedangkan sekitar $78 \%$ tanaman obat diperoleh dengan penambangan dari hutan. Hal ini akan berpengaruh pada kemampuan pasokan atas pemenuhan permintaan serta berakibat pada kelangkaan beberapa jenis tanaman obat. Beberapa tanaman obat yang mulai langka di Indonesia antara lain jinten, temugiring, jatibelanda, bidara laut, bangle, kedawung dan pasak bumi. Keanekaragaman jenis tanaman obat menuntut kondisi lingkungan yang sesuai untuk pembudidayaannya. Setiap jenis tanaman berkhasiat obat membutuhkan kondisi lingkungan tertentu agar dapat tumbuh dan berkembang secara optimal. Beberapa unsur iklim seperti suhu, curah hujan dan penyinaran matahari secara langsung berpengaruh bagi pertumbuhan tanaman. Untuk mempermudah penggunaan tanaman berkhasiat obat pada masyarakat maka perlu dilakukan sosialisasi terkait dengan TOGA (Tanaman Obat Keluarga).

TOGA atau tanaman obat keluarga pada dasarnya adalah program pemanfaatan sebidang tanah baik di halaman rumah, kebun maupun ladang untuk membudidayakan tanaman yang berkhasiat sebagai obat. Selain dapat digunakan untuk memenuhi keperluan keluarga akan obat-obatan, TOGA juga dapat digunakan sebagai penghias halaman rumah. Tanaman seperti kunyit, jahe, temulawak, lengkuas, jeruk purut adalah contoh dari TOGA yang mudah ditanam di perkarangan rumah. Tanaman-tanaman obat ini dapat dikembangkan untuk pengobatan penyakit sehari-hari seperti batuk, masuk angin, flu, dan panas dalam, maupun untuk beberapa penyakit yang lebih berat seperti kanker, tumor dan sebagainya. Dewasa ini, tanaman obat tidak hanya digunakan untuk pengobatan penyakit, namun juga dikembangkan juga sebagai kosmetika alami untuk menjaga kecantikan dan kesehatan kulit serta tubuh (Muhlisah, 2000; Tukiman, 2004).

Desa tembobor merupakan salah satu desa yang berada di Kecamatan Pamenang, Kabupaten Lombok Utara. Pemanfaatan TOGA dirasa tidak maksimal dikarenakan kurangnya pengetahuan mengenai khasiat dan cara penggunaan TOGA untuk pengobatan. Masyarakat di desa ini mempunyai pekarangan rumah yang luas namun belum dimanfaatkan secara maksimal. Dengan adanya informasi mengenai khasiat yang ditawarkan oleh TOGA diharapkan masyarakat dapat menanam dan memanfaatkan TOGA untuk pengobatan dengan maksimal sehingga dapat menuju masyarakat Indonesia yang sehat.

\section{METODE PELAKSANAAN}

Secara umum, metode
pelaksanaan yang digunakan dalam
pengabdian pada masyarakat ini adalah
sosialisasi pemanfaatan, praktik langsung
pembuatan ramuan obat serta penanaman


DOI: https://doi.org/10.21009/sarwahita.151.07

P-ISSN: 0216-7484

E-ISSN: 2597-8926

TOGA. Tahapan pelaksanaan kegiatan dapat diuraikan sebagai berikut :

1. Tim melakukan koordinasi pada elemen masyarakat terkait waktu dan tujuan pelaksanaan kegiatan pengabdian.

2. Penyuluhan/sosialisasi dilakukan pada tanaman TOGA terpilih. Tanaman TOGA ini relative mudah didapatkan, mudah ditanaman dan dijual dengan harga yang terjangkau. Tanaman sosialisasi antara lain, kunyit, temulawak, kencur, jahe, jahe merah, sambiloto, kumis kucing dan daun katuk.

3. Penyuluhan/sosialisasi dilakukan dengan penyampaian materi dan diselingi tanya jawab dari peserta.

4. Sosialisasi dilakukan juga dalam bentuk penyebaran leaflet/brosur mengenai beberapa jenis tanaman obat yang dijelaskan.

5. Demonstrasi/praktek pembuatan ramuan pengobatan yaitu beras kencur dan kunyit asem. Peserta juga diberikan resep pembuatannya.
6. Inisiasi pembuatan taman TOGA disalah satu pekarangan warga desa tembobor.

\section{HASIL DAN PEMBAHASAN}

\section{A. Koordinasi dan persiapan kegiatan}

Pelaksanaan kegiatan dilakukan di desa Tembobor, kecamatan Pamenang, Kabupaten Lombok Utara. Koordinasi dengan perangkat desa dilakukan oleh tim dengan jalan diskusi. Dari diskusi ditentukan waktu pelaksanaan, tempat pelaksanaan serta peserta yang akan diundang.

Persiapan dimulai dari penyusunan dan penetapan materi sosialisasi kemudian melakukan percobaan untuk membuat satu ramuan pengobatan yang akan dipraktekkan.

Pada hari dilaksanakan program warga diawal diminta untuk mendaftarkan diri guna pembuktian administrasi. Pada proses pendaftaran peserta akan mendapatkan leaflet tentang beberapa TOGA yang akan disosialisasikan.

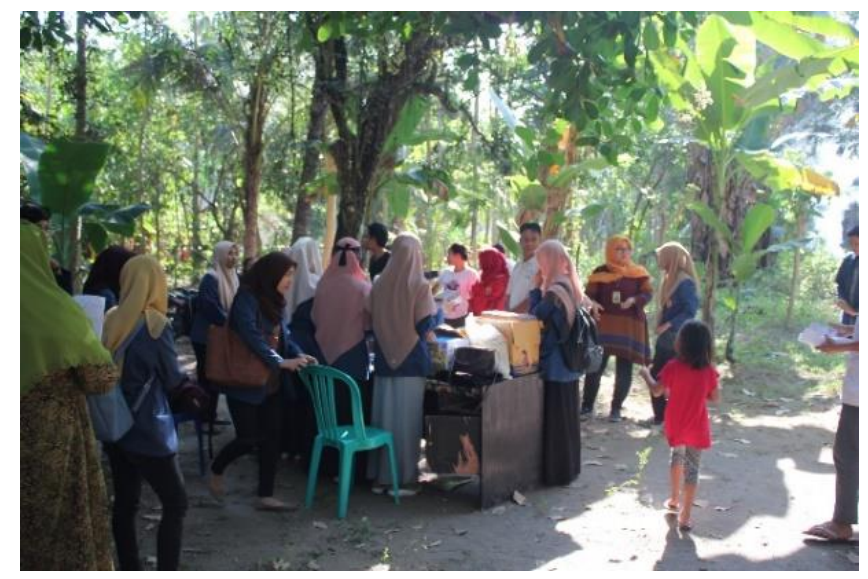

Gambar 1. Pendaftaran peserta awal

Tanaman yang akan disosialisasikan dipastikan telah tersedia agar masyarakat dapat memahami perbedaan anatomi pada TOGA yang dimaksud. 
DOI: https://doi.org/10.21009/sarwahita.151.07

P-ISSN: 0216-7484

E-ISSN: 2597-8926

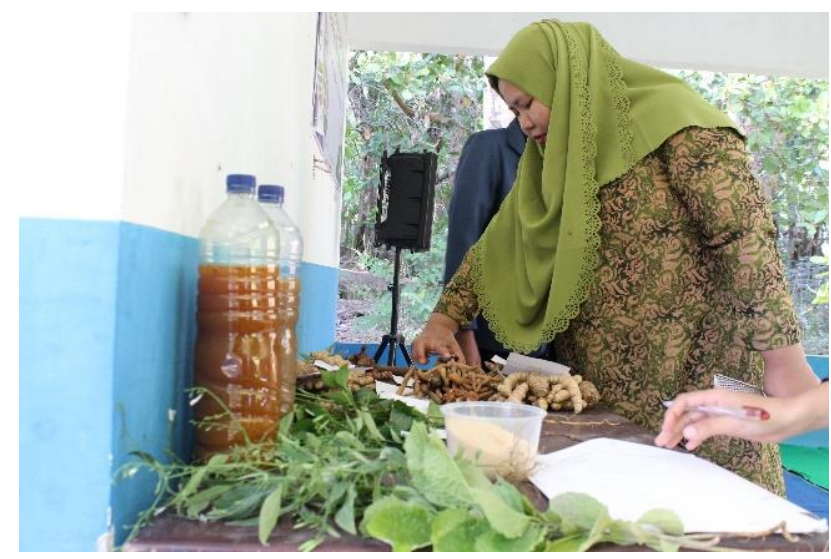

Gambar 2. Pengaturan tanaman

\section{B. Sosialisasi dan penyuluhan}

Sosialisasi dilakukan dengan metode interaktif menggunakan LCD proyektor dan power point sebagai media. Sebanyak 40 orang warga tercatat mengikuti sosialisasi yang diadakan di pos posyandu pembantu di desa Tembobor.
Materi sosialisasi meliputi pengertian TOGA, beberapa tanaman yang termasuk TOGA, khasiat dan cara pengolahan tanaman untuk pengobatan. Berikut adalah daftar tanaman pilihan untuk sosialisasi (Tabel I). Dipilihnya tanaman tersebut dikarenakan kemudahannya dalam didapatkan dan penanamannya.

Tabel I. Tanaman Pada Sosialisai TOGA

\begin{tabular}{|c|c|c|}
\hline \multirow{2}{*}{ No } & \multicolumn{2}{|r|}{ Tanaman dan Kagunaannya } \\
\hline & Nama & Kegunaan Umum \\
\hline 1 & Kunyit & $\begin{array}{l}\text { Secara tradisional di gunakan untuk mengatasi demam, hidung } \\
\text { tersumbat (akibat pilek), rematik, diare, disentri, hiperlipidemia, } \\
\text { nyeri dada, asma, dyspepsia, haid tidak teratur, radang, jaundice } \\
\text { (sakit kuning) dan hipertensi. }\end{array}$ \\
\hline 2 & Temulawak & $\begin{array}{l}\text { Secara tradisional di gunakan untuk mengatasi hepatitis, sakit } \\
\text { kuning, radang ginjal, perut kembung, tidak nafsu makan, } \\
\text { demam, pegal linu, rematik, sembelit, hiperkolesterol, haid tidak } \\
\text { lancer dan wasir }\end{array}$ \\
\hline 3 & Lengkuas & $\begin{array}{l}\text { Secara tradisional di gunakan untuk mengatasi haid tidak lancer, } \\
\text { pegal linu, masuk angina, diare, tidak nafsu makan, demam, } \\
\text { menghilangkan bau mulut, sariawan, sakit tenggorokan, batuk } \\
\text { berdahak, radang paru dan sakit telinga. }\end{array}$ \\
\hline 4 & Jahe & $\begin{array}{l}\text { Secara tradisional di gunakan untuk mengatasi mual dan muntah, } \\
\text { diare, perut kembung, demam, batuk berdahak, flu, pegal linu, } \\
\text { tidak nafsu makan serta kesemutan pada tangan dan kaki. }\end{array}$ \\
\hline 5 & Sambiloto & $\begin{array}{l}\text { Secara tradisional di gunakan untuk mengatasi hepatitis, infeksi } \\
\text { saluran empedu, diare, disentri, tifoid, peradangan, asma, } \\
\text { hipertensi dan kusta. }\end{array}$ \\
\hline 6 & Kumis Kucing & $\begin{array}{l}\text { Secara tradisional di gunakan untuk mengatasi infeksi ginjal akut } \\
\text { dan kronis, infeksi kandung kencing, kencing batu, hipertensi dan } \\
\text { tekanan darah tinggi. }\end{array}$ \\
\hline 7 & Daun Katuk & $\begin{array}{l}\text { Secara tradisional di gunakan untuk mengatasi ASI yang tidak } \\
\text { lancer. }\end{array}$ \\
\hline
\end{tabular}




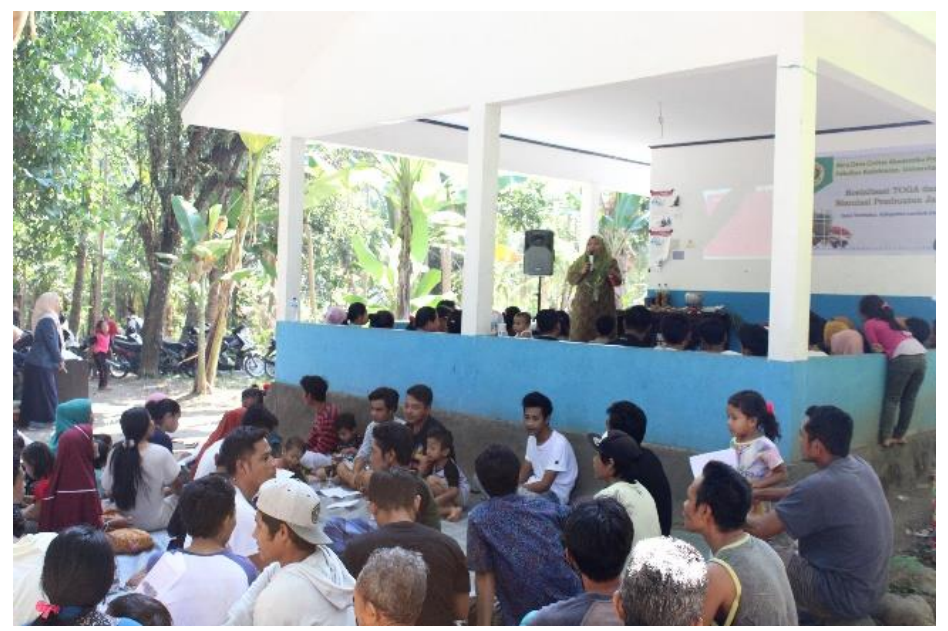

Gambar 3. Suasana peserta sosialisasi TOGA

Warga desa pada saat proses sosialisasi terlihat sangat memperhatikan. Beberapa pertanyaan sempat dilontarkan oleh masyarakat desa terkait dengan kebenaran dari suatu tanaman dikarenakan perbedaan nama lokal dan nama daerah dari tanaman misalnya daun katuk, nama lokalnya adalah daun sager. Beberapa warga pun menanyakan ulang khasiat beberapa tanaman yang mereka ketahui namun tidak ada di penjelasan seperti khasiat kencur (dapat digunakan untuk pengobatan batuk).

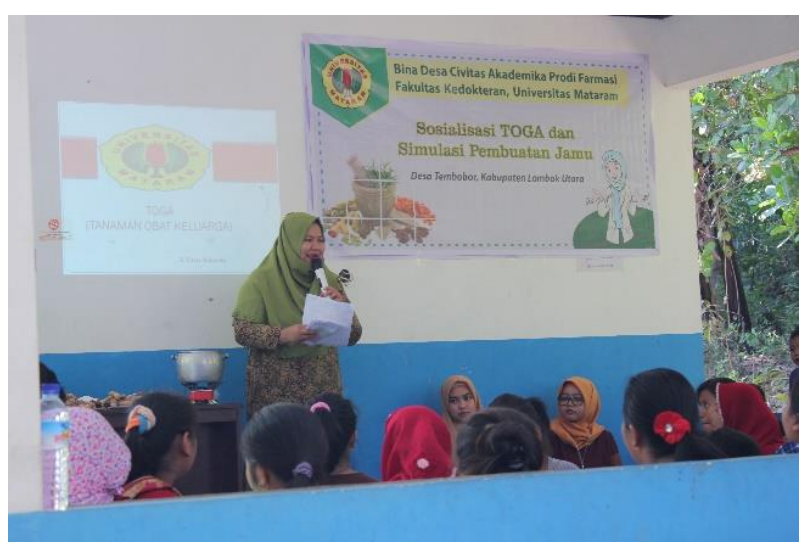

Gambar 4. Sosialisasi dilakukan oleh tim program pengabdian.

\section{Praktik Pembuatan Ramuan}

Warga tidak hanya dituntut untuk manfaat TOGA saja namun juga harus mengetahui bagaimana cara pengolahannya dan komposisinya dalam suatu ramuan pengobatan. Kesalahan dalam pengolahan dapat menyebabkan ramuan tidak memiliki khasiat yang diinginkan. Adapaun kesalahan pengolahan biasanya terjadi karena minimnya pengetahuan masyarakat yang disebabkan karena tidak adanya sosialisasi dari pemerintah ataupun literatur terkait. 


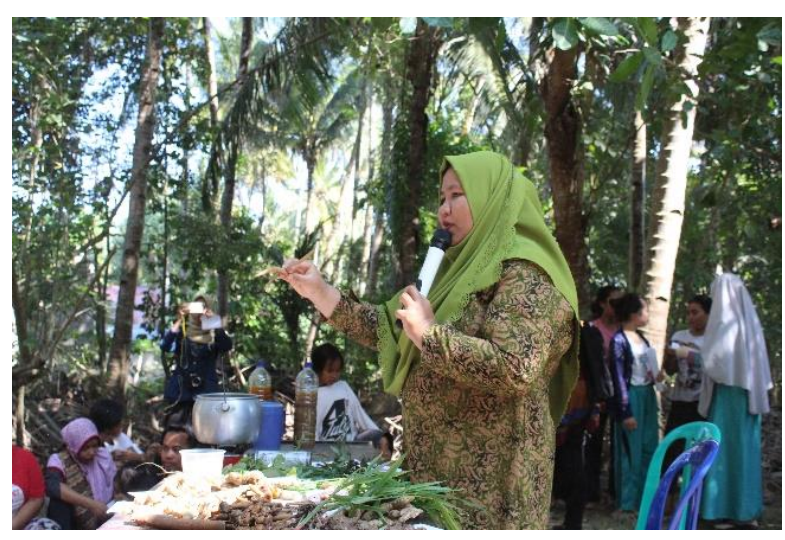

Gambar 5. Penjelasan dalam pengolahan tanaman obat

Adapun hal-hal yang harus diperhatikan dalam pengolahan tanaman obat adalah :

1. Bahan tanaman yang digunakan untuk obat harus dalam keadaan segar. Bila menggunakan bahan kering maka harus dipastikan bahan dalam keadaan bagus (tidak berjamur). Semua bahan haruslah dicuci dengan air bersih (tidak berlaku untuk bahan minyak dan serbuk).

2. Peralatan yang digunakan haruslah dalam keadaan bersih. Pencucian wajib dilakukan untuk menghilangkan kotoran yang berpotensi dalam kontaminasi.

3. Penggunaan air diharuskan bersumber dari tempat bersih dan

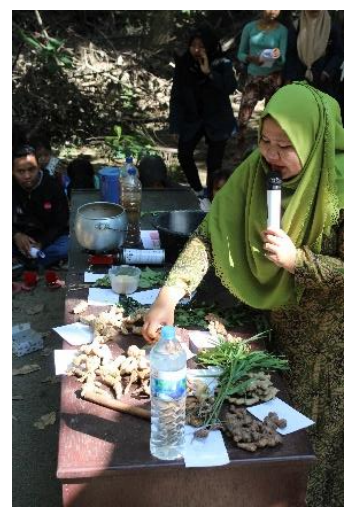

Gambar 6. Praktek cara membuat jamu. dimasak terlebih dahulu, kecuali jika pembuatan ramuan dilakukan dengan perebusan.

4. Waktu penyimpanan ramuan yang diproses dengan cara memeras maksimal adalah 12 jam dan untuk rebusan adalah 24 jam. Setelah batas waktu tersebut ramuan tidak dapat dikonsumsi.

5. Walau pemakaian obat tradisional dianjurkan sebagai tindakan pengobatan penyakit, maka tidak berarti pengobatan medis atau dokter diabaikan. Apabila ada pasien penderita penyakitnya parah harusnya segara dirujuk ke rumah sakit/puskesmas/dokter terdekat untuk mendapat pertolongan.

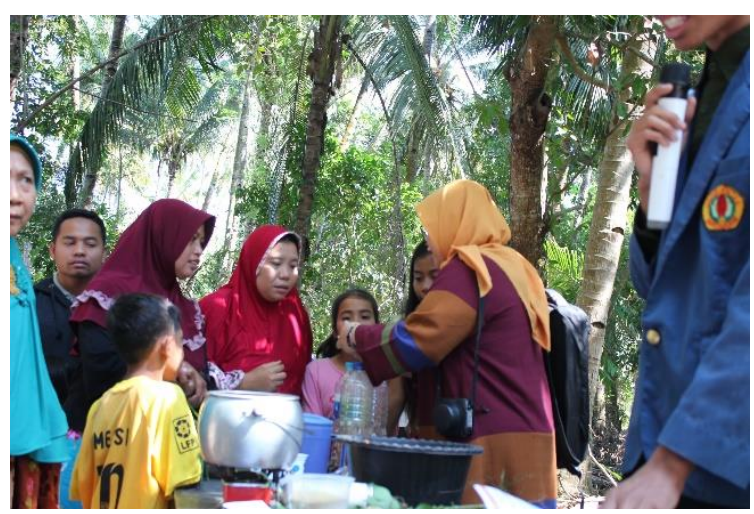

Gambar 7. Pemberian hasil ramuan 
DOI: https://doi.org/10.21009/sarwahita.151.07

P-ISSN: 0216-7484

E-ISSN: 2597-8926

\section{Inisiasi taman TOGA}

Tahap akhir program adalah melakukan inisiasi taman TOGA yang ditempatkan pada salah satu pekarangan warga. Beberapa jenis tanaman yang diberikan adalah, jahe, sambiloto, cocor bebek, kumis kucing dan cabe jawa.

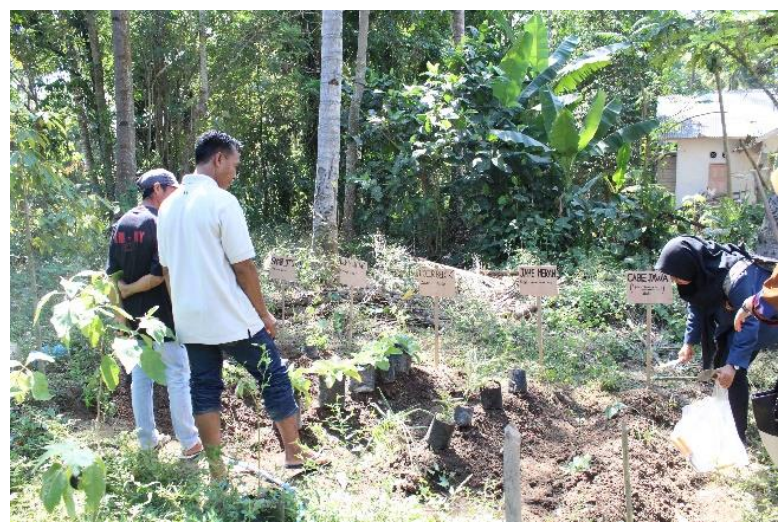

Gambar 8. Penanaman TOGA

Dalam proses ini diberikan penjelasan mengenai khasiat tanaman dan cara menanam serta merawatnya. Hal yang perlu diperhatikan pula adalah penjelasan bagian tanaman yang digunakan sebagai obat dan kapan saatnya tanaman tersebut dapat dipanen, misalnya saja untuk rimpang-rimpangan dapat dipanen pada saat sudah tidak berbunga dan bagian atas tanaman mulai mengering, sedang untuk daun seperti sambiloto dan kumis kucing dapat dipetik daunnya pada pagi hari setelah embun menguap, daun yang diambil bukanlah daun muda (Anonim, 2000).

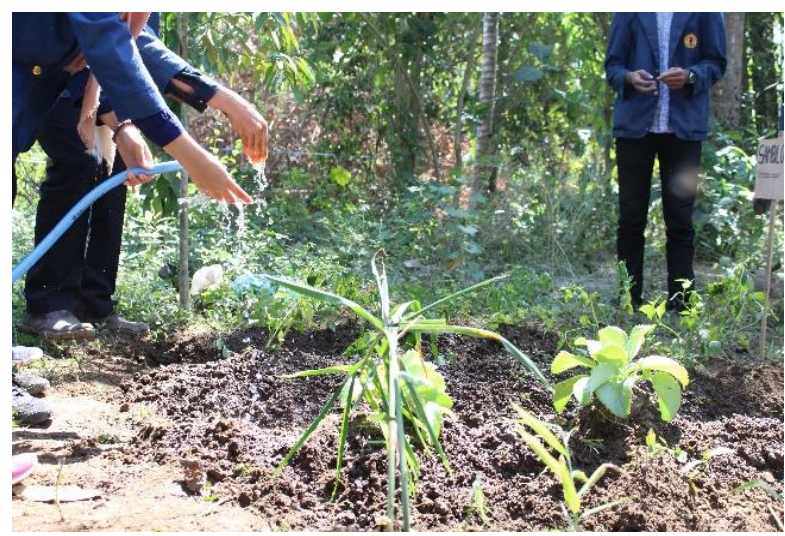

Gambar 9. Penyiraman TOGA

\section{PENUTUP}

Berdasarkan kegiatan yang pengabdian yang telah dilakukan dapat disimpulkan bahwa :

1. Tahapan program pengabdian masyarakat di Desa Tembobor terdiri atas : koordinasi, sosiasilasi TOGA, praktek pembuatan ramuan pengobatan, inisiasi taman TOGA telah dilaksanakan sesuai dengan rencana.

2. Pelaksanaan sosialisasi TOGA dan pembuatan ramuan pengobatan 
DOI: https://doi.org/10.21009/sarwahita.151.07

P-ISSN: 0216-7484

E-ISSN: 2597-8926

mendapat respon positif dari warga

Desa Tembobor yang dapat dilihat dari antusiasme kedatangan peserta hingga menempati area diluar pos posyandu. Warga juga terlihat aktif dalam memberikan pertanyaan tentang TOGA kepada pemateri.

3. Inisiasi taman TOGA telah dilaksanakan pada salah satu pekarangan warga. Diharapakan taman TOGA ini dapat dijadikan percontohan warga pada saat menanam TOGA.

\section{DAFTAR PUSTAKA}

Anonim. (2000). Parameter Standar
Umum Ekstrak Tumbuhan Obat (1st ed.). Jakarta: Departemen Kesehatan Republik Indonesia.

Muhlisah, F. (2000). Taman Obat Keluarga (TOGA). Jakarta: Penebar Swadaya.

Peraturan Menteri Kesehatan Republik Indonesia. Standar Pelayanan Medik Herbal, Pub. L. No. 121 (2008).

Tukiman. (2004). Pemanfaatan Tanaman Obat Keluaraga (TOGA) Untuk Kesehatan Keluarga. Medan: Bagian Pendidikan Kesehatan dan Ilmu Perilaku Fakultas Kesehatan Masyarakat Universitas Sumatera Utara. 